\title{
The relation between ambulance transports due to heat stroke and air temperature using daily data in Okayama prefecture, Japan
}

\author{
Nobuyuki Miyatake*, Noriko Sakano, Shoko Murakami \\ Department of Hygiene, Faculty of Medicine, Kagawa University, Miki, Kagawa, Japan; \\ *Corresponding Author: miyarin@med.kagawa-u.ac.jp
}

Received 18 October 2011; revised 20 November 2011; accepted 26 December 2011

\begin{abstract}
The aim of this study was to investigate the link between ambulance transports due to heat stroke and air temperature by using daily data of ambulance transports in Okayama prefecture, Japan. Daily observations for ambulance transports due to heat stroke from July to September in 2010 in Okayama prefecture, Japan were obtained from Fire and Disaster Management Agency in Japan. Data of meteorological parameters in Okayama prefecture, Japan were also obtained from Japan Meteorological Agency. Effect of meteorological parameters on ambulance transports due to heat stroke was analyzed. A total of 1133 ambulance transports due to heat stroke were observed in from July to September of 2010 in Okayama prefecture, Japan. Ambulance transports due to heat stroke was significantly correlated with air temperature. In addition, number of subjects with ambulance transports due to heat stroke over $34^{\circ} \mathrm{C}$ in the highest air temperature was $21.2 \pm 9.8$ per day. Higher air temperature was closely associated with higher ambulance transports due to heat stroke by using daily data in Okayama, prefecture, Japan.
\end{abstract}

Keywords: Heat Stroke; Ambulance Transports; Okayama; Air Temperature; Daily Data

\section{INTRODUCTION}

Global warming has become public health challenge and heat stroke is considered to be severe problem according to global warming [1]. We have previously showed that estimated changes in mean temperature was $2.05^{\circ} \mathrm{C}$ for 50 years in Okayama city, Okayama prefecture, Japan [2]. In addition, using monthly data of total ambulance transports, higher air temperature was closely associated with higher total ambulance transports in Okayama [3] and Taka- matsu [4] area, Japan. In addition, ambulance transports due to heat stroke was closely linked to higher air temperature in all 47 prefectures in Japan by ecological study [5]. However, the link between heat stroke and air temperature by using daily data still remains to be investigated in Okayama prefecture, Japan.

Therefore, we investigate the relationship between ambulance transports due to heat stroke and air temperature by using daily data in Okayama prefecture, Japan.

\section{METHODS}

\subsection{Study Area}

The Sanyo Highway, the three large rivers and the Seto Inland Sea, used as water transportation, all have made Okayama an important location for transportation between the Chugoku-Shikoku regions. These conditions have largely contributed to the development of various industry, business and culture, which have flourished from the ancient Kibi times to present. Okayama prefecture $(1,957,264$ people) is steadily developing as the cross-point for the Chugoku-Shikoku region because of its interstate highways which stretch in all directions of the prefecture, the Okayama airport which flies both international and domestic, and also railway and bullet train accesses to the East, West, South and North of Japan [6].

\subsection{Ambulance Data}

Daily incidence data of ambulance transports due to heat stroke from July to September in 2010 was directory obtained from Fire Department Service, Japan [7].

\subsection{Meteorological Parameters}

Daily meteorological parameters in Okayama, prefecture, Japan for the required periods were obtained from Japan Meteorological Agency. The observation spots (Okayama) were located at the central in the area. Daily meteorological parameters i.e. mean temperature $\left({ }^{\circ} \mathrm{C}\right)$, the hi- 
ghest air temperature $\left({ }^{\circ} \mathrm{C}\right)$ and the lowest air temperature $\left({ }^{\circ} \mathrm{C}\right)$ were used for analysis [8].

\subsection{Statistical Analysis}

Data are expressed as means \pm standard deviation (SD) values. Comparisons among more than three groups were performed by one factor analysis of variance (ANOVA) and Scheffe's F test. $P<0.05$ was considered to indicate statistical significance. The simple and polynomial correlation analyses were calculated to test for the significance of the linear relationship among continuous variables.

\section{RESULTS}

Profiles of using daily data of ambulance transports in Okayama prefecture, Japan in from July to September in 2010 were summarized in Table 1. A total of 1133 ambulance transports due to heat stroke were observed from
July to September in 2010 in Okayama prefecture, Japan. Mean ambulance transports due to heat stroke was $12.3 \pm$ 11.0/day (Table 1).

We evaluated the relationship between ambulance transports due to heat stroke and air temperature by using daily data (Table 2). Ambulance transports due to heat stroke was positively correlated with parameters of air temperature. In addition, the coefficient rate between ambulance transports due to heat stroke and mean air temperature was the highest among variables $(\mathrm{r}=0.737, P<0.0001)$.

We also compared ambulance transports due to heat stroke as classified by mean temperature (Table 3) and the highest temperature (Table 4). Ambulance transports due to heat stroke was significantly higher over $29^{\circ} \mathrm{C}$ in mean temperature than those under $26^{\circ} \mathrm{C}$ (Table 3). Ambulance transports due to heat stroke was also significantly higher over $33^{\circ} \mathrm{C}$ in the highest air temperature than those under $30^{\circ} \mathrm{C}$ (Table 4).

Table 1. Clinical parameters of ambulance transports due to heat stroke and air temperature from July to September in 2010 in Okayama prefecture, Japan.

\begin{tabular}{|c|c|c|c|c|c|}
\hline & Mean & \pm & $\mathrm{SD}$ & Minimum & Maximum \\
\hline Number of days & & 92 & & & \\
\hline Ambulance transports stratified by heat stroke (/day) & 12.3 & \pm & 11.0 & 0 & 44 \\
\hline Mean air temperature $\left({ }^{\circ} \mathrm{C}\right)$ & 28.2 & \pm & 3.1 & 18.3 & 31.9 \\
\hline The highest air temperature $\left({ }^{\circ} \mathrm{C}\right)$ & 32.6 & \pm & 3.7 & 19.2 & 37.9 \\
\hline The lowest air temperature $\left({ }^{\circ} \mathrm{C}\right)$ & 24.6 & \pm & 3.1 & 15.5 & 28.5 \\
\hline
\end{tabular}

Table 2. Simple correlation analysis between ambulance transports due to heat stroke and air temperature from July to September in Okayama prefecture, Japan.

\begin{tabular}{lccccc}
\hline & $\mathrm{r}$ & $P$ & Regression line & $\mathrm{y}$ & $\mathrm{x}$ \\
\hline Mean air temperature $\left({ }^{\circ} \mathrm{C}\right)$ & 0.737 & $<0.0001$ & $\mathrm{y}=2.612 \mathrm{x}-61.344$ & Heat stroke $(/$ day $)$ & Mean air temperature $\left({ }^{\circ} \mathrm{C}\right)$ \\
The highest air temperature $\left({ }^{\circ} \mathrm{C}\right)$ & 0.724 & $<0.0001$ & $\mathrm{y}=2.179 \mathrm{x}-58.691$ & Heat stroke $(/$ day $) \quad$ The highest air temperature $\left({ }^{\circ} \mathrm{C}\right)$ & Heat stroke $(/$ day $) \quad$ The lowest air temperature $\left({ }^{\circ} \mathrm{C}\right)$ \\
The lowest air temperature $\left({ }^{\circ} \mathrm{C}\right)$ & 0.689 & $<0.0001$ & $\mathrm{y}=2.486 \mathrm{x}-48.744$ &
\end{tabular}

Table 3. Comparison of ambulance transports due to heat stroke as classified by mean air temperature.

\begin{tabular}{|c|c|c|c|c|c|c|}
\hline \multicolumn{2}{|c|}{$\begin{array}{c}\text { Mean air } \\
\text { temperature }\left({ }^{\circ} \mathrm{C}\right)\end{array}$} & \multirow{2}{*}{$\begin{array}{c}\text { Number of days } \\
18\end{array}$} & \multirow{2}{*}{$\begin{array}{c}\text { Mean } \\
0.9\end{array}$} & \multirow{2}{*}{$\begin{array}{l} \pm \\
\pm\end{array}$} & \multicolumn{2}{|l|}{$\mathrm{SD}$} \\
\hline$<26$ & & & & & 1.1 & \\
\hline $26 \leq$ & $<27$ & 9 & 2.9 & \pm & 1.6 & \\
\hline $27 \leq$ & $<28$ & 7 & 6.0 & \pm & 3.3 & \\
\hline $28 \leq$ & $<29$ & 8 & 8.4 & \pm & 6.2 & \\
\hline $29 \leq$ & $<30$ & 13 & 12.7 & \pm & 3.8 & $\mathrm{a}$ \\
\hline $30 \leq$ & & 37 & 22.1 & \pm & 9.8 & $\begin{array}{c}\mathrm{a}, \mathrm{b}, \mathrm{c}, \mathrm{d}, \\
\mathrm{e}\end{array}$ \\
\hline
\end{tabular}

a: $P<0.05$ vs $<26$; b: $p<0.05$ vs $26 \leq<27$; c: $P<0.05$ vs $27 \leq<28$; d: $P<$ 0.05 vs $28 \leq<29$; e: $P<0.05$ vs $29 \leq<30$.
Table 4. Comparison of ambulance transports due to heat stroke as classified by the highest air temperature.

\begin{tabular}{|c|c|c|c|c|c|c|}
\hline \multicolumn{2}{|c|}{$\begin{array}{l}\text { The highest air } \\
\text { temperature }\left({ }^{\circ} \mathrm{C}\right)\end{array}$} & \multirow{2}{*}{$\begin{array}{c}\text { Number of days } \\
17\end{array}$} & \multirow{2}{*}{$\begin{array}{c}\text { Mean } \\
0.8\end{array}$} & \multirow{2}{*}{$\begin{array}{l} \pm \\
\end{array}$} & \multicolumn{2}{|l|}{ SD } \\
\hline$<30$ & & & & & 1.1 & \\
\hline $30 \leq$ & $<31$ & 3 & 2.7 & \pm & 0.6 & \\
\hline $31 \leq$ & $<32$ & 8 & 3.3 & \pm & 1.7 & \\
\hline $32 \leq$ & $<33$ & 11 & 7.2 & \pm & 5.6 & \\
\hline $33 \leq$ & $<34$ & 14 & 12.8 & \pm & 5.7 & $\mathrm{a}$ \\
\hline $34 \leq$ & & 39 & 21.2 & \pm & 9.8 & $\mathrm{a}, \mathrm{b}, \mathrm{c}, \mathrm{d}, \mathrm{e}$ \\
\hline
\end{tabular}


We finally evaluated the relationship between ambulance transports due to heat stroke and the highest air temperature by using polynomial regression analysis. Ambulance transports due to heat stroke were significantly correlated with the highest air temperature in Okayama prefecture, Japan [(Ambulance transports due to heat stroke) $=0.015$ (the highest air temperature) $^{3}-1.087$ (the highest air temperature $)^{2}+25.317$ (the highest air temperature) 192.287; $\mathrm{r}=0.844, P<0.0001$ ] (Figure 1).

\section{DISCUSSION}

We firstly evaluated the association between ambulance transports due to heat stroke and meteorological parameters by using daily data of ambulance transports in 2010 in Okayama prefecture, Japan. Higher air temperature was closely and accurately linked to ambulance transports due to heat stroke by using daily data.

We have previously reported that higher air temperature was closely linked to higher ambulance transports by using monthly data of total ambulance transports in Okayama city, Okayama prefecture, Japan [3]. Correlation coefficient rate between total ambulance transports and the highest air temperature in a month was $0.722(P=0.0024)$. In addition, total ambulance transports were also signifycantly correlated with the number of days over $32^{\circ} \mathrm{C}(\mathrm{r}=$ $0.674, P=0.0059$ ) [3]. By ecological study, various parameters of air temperatures i.e. mean of the mean air temperatures, mean of the highest air temperatures, mean of the lowest air temperatures, the highest air temperature and the lowest air temperature in August, 2009 were significantly and positively correlated with ambulance transports by heat stroke (per total ambulance transports and per 10 thousand person) in 47 prefectures in Japan combined [5]. Therefore, previous our study was not accurately analyzed the link between heat stroke and air temperature because by using monthly and daily data of total ambulance transports or by ecological study. Bai et al. also showed that the number of unusual deaths in the summer of 1994 in Osaka, Japan was more compared to those of previous year [9]. In this study, we more accurately showed that, by using daily data of ambulance transports due to heat stroke, ambulance transports due to heat stroke was significantly correlated with air temperature. In addition, ambulance transports due to heat stroke over $34^{\circ} \mathrm{C}$ in the highest air temperature was $21.2 \pm 9.8$ /day in Okayama, prefecture, Japan. In addition, by using our formula of polynomial regression line, we can estimate the number of ambulance transports due to heat stroke. Therefore, it is reasonable that we need to deal with high air temperatures in summer in Okayama prefecture i.e. individual coping with high air temperatures, innovation of the thermal energy metabolism in cities and preparation of ambulance transports system.

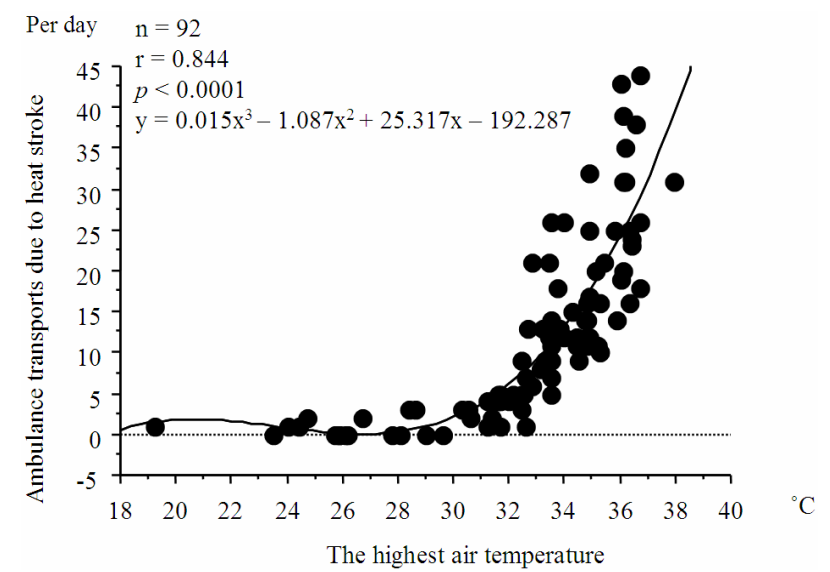

Figure 1. The relationship between ambulance transports due to heat stroke and the highest air temperature by using polynomial correlation analysis from July to September in 2010 in Okayama prefecture, Japan.

Potential limitations still remain in this study. First, the link between ambulance transports due to heat stroke and air temperatures, which was noted in this study, may not apply for the link among individuals. Second, we could not directly evaluate various air temperature parameters in various sites in Okayama prefecture, Japan. Further studies are required to prove such link.

\section{ACKNOWLEDGEMENTS}

This research was supported in part by Research Grants from FUKUTAKE Science \& Culture Foundation, Japan.

\section{REFERENCES}

[1] Kalkstein, L.S. and Greene, J.S. (1997) An evaluation of climate/mortality relationships in large US cities and the possible impacts of a climate change. Environmental Health Perspecttives, 105, 84-93.

doi:10.1289/ehp.9710584

[2] Sakano, N., Miyatake, N., Murakami, S., Suzue, T., Hirao, T. and Ogino, K. (2011) Changes in temperatures in Okayama area compared with different urbanization areas, Japan. Journal of Environtal Protection, 2, 162-167. doi:10.4236/jep.2011.22018

[3] Sakano, N., Miyatake, N., Suzue, T., Suna, S., Hirao, T. and Ogino, K. (2011) The relation between high temperatures and ambulance transports in Okayama city, Japan. Journal of Preventive Medicine, 6, 17-20.

[4] Miyatake, N., Nakao, M., Sakano, N., Suna, S., Suzue, T. and Hirao, T. (2011) Higher ambulance transports were closely associated with higher ambulance transports in Takamatsu area, Japan. Journal of Environmental Protection, 2, 72-75. doi:10.4236/jep.2011.21007

[5] Miyatake, N., Sakano, N. and Murakami, S. (2012) The relation between ambulance transports stratified by heat stroke and air temperature in all 47 prefectures of Japan in August 2009: Ecological study. Environmental Health 
and Preventive Medicine, 17, 77-80.

[6] Okayama prefecture, Japan (2011). http://www.pref.okayama.jp/kikaku/kokusai/momo/e/gaiy ou/gaiyou.html

[7] Fire and Disaster Management Agency, Japan (2011). http://jsem.umin.ac.jp/pdf/heat qqhansouteikyou.pdf\#sea $\underline{\mathrm{rch}}=$

[8] Japan Meteorological Agency (2011). http://www.data.jma.go.jp/obd/stats/etrn/index.php?prec no=66\&prec $\mathrm{ch}=\% 89 \% \mathrm{AA} \% 8 \mathrm{ER} \% 8 \mathrm{C} \% \mathrm{~A} 7 \&$ block no= 47768\&block $\mathrm{ch}=\% 89 \%$ AA $\% 8$ ER\&year $=2010 \&$ month $=$ \&day $=\&$ elm $=\&$ view $=$

[9] Bai, H., Islam, M.N., Kuroki, H., Honda, K. and Wakasugi, C. (1995) Deaths due to heat waves during the summer of 1994 in Osaka prefecture, Japan. Nihon Hoigaku Zasshi, 49, 265-274. 